\title{
In search of lost time: age and the promise of induced pluripotent stem cell models of the brain
}

\section{Introduction}

Concerns about the ageing of the global population have long encompassed an 'apocalyptic demography' (Robertson 1990) populated by imaginaries of a 'zombie future' of elderly people with dementia (Behuniak 2011). Such concerns are at the heart of a surge of national and international political and economic engagement with neurodegenerative diseases, dementia, and particularly Alzheimer's disease (OECD 2015; National Institute on Aging 2012). In June 2014, then UK Prime Minster David Cameron gave a speech to an audience of world health and finance leaders assembled for the G8, in which he promised "a global fight-back against dementia" (Cameron 2014). He outlined a techno-optimistic vision of how this future would be averted through increased funding for dementia research:

“Earlier today our World Dementia Envoy Dr Dennis Gillings talked about his visit to University College London where he witnessed the amazing sight of neurons from stem cells firing in a petri dish - replicating the functioning of the brain. We don't yet know anything like enough about how the brain becomes diseased. But already we can begin to model how it functions. So we should just imagine what could be achieved in the coming years." (Cameron 2014, no page; emphasis added)

The amazing neurons in a dish are presented as a gateway to a new future. More recently, the potential of "Alzheimer's in a dish" derived from induced pluripotent stem cells (iPSCs) is identified as an eye-catching example of progress in the National Institute of Health's 2015 proposal for future Alzheimer's research, entitled 'Reaching for a Cure' (National Institutes of Health 2015).

Over the last decade, stem cells have become the postgenomic 'translational object of choice' (Maienschein et al. 2008). Stem cell research promises health and wealth from "harnessing the pluripotent power of recombinant regenerativity" (Franklin 2006, 171) in a move to regenerative medicine and cell transplants (Wainwright, Michael, and Williams 2008; Prainsack, Geesink, and Franklin 2008; P. Martin, Brown, and Turner 2008). Cells such as those described by Cameron and the NIH build on a second wave of hype and expectation associated with the 'reprogramming' of adult cells to become pluripotent (Hauskeller and Weber 2011). In 2006, Japanese researchers led by Shinya Yamanaka demonstrated that four factors delivered into cells using a virus could drive a process of 'rejuvenating' cells, reverting them to a quasi-embryonic state.

The hopes and expectations attached to stem cells reflect the wider significance of promissory narratives in contemporary bioscience (Borup, Brown, and Konrad 2006; Brown and Michael 2003). Socio-technical development is saturated with formal and informal anticipations, promises and expectations which shape research questions, funding commitments and institutional orderings around new technologies, including pharmacogenetics research related to Alzheimer's disease (Hedgecoe and Martin 2003; Hedgecoe 2006).

In this paper, I explore how the promise of iPSC-derived 'neurons in a dish' emerges through the process of 'bio-objectification', through which living entities - in this case people with neurodegenerative diseases - are made into objects through scientific labour and technologies, and come to be attributed with specific identities and qualities (Vermeulen, Tamminen, and Webster 2012). Bio-objects are tangible outputs of the life sciences that can be leveraged, stored, circulated and exchanged, which are imbued with hope and expectations, which straddle or trouble conventional boundaries and are able to transition between domains of application (Metzler and Webster 2011; Holmberg, Schwennesen, and Webster 2011). In this paper, I argue that the promise of iPSCs emerges as researchers articulate and contest their ability to sit across problematic lines in neurodegenerative disease research - particularly those between the patient and the model and between normal and pathological ageing.

In the paper, I examine how the promise of iPSCs is established through their ability to translate the characteristics of 'real' patients and model 'real' disease pathology into the lab. I then argue that this promise is destabilised through disputes about the significance of 'ageing' in neurodegeneration contest. I examine 
how 'ageing' is practised, materialised, and reworked in response to these contestations, stabilising the promise of the technology and producing the 'aged cell' emerges as a tangible, exchangeable output.

The paper is informed by a period of ethnographic observation in a neuroscience laboratory, and at conferences and meetings on Alzheimer's disease and other neurodegenerative disorders between April and December 2014. This research focussed on the 'translational' relationship between laboratory and clinic, and the historical, practical and material genealogies of research practice (cf Landecker 2009b). Throughout this work iPSCs consistently emerged as a focus of research interest and of future research plans. This paper aims to contextualise this interest, by exploring the emergence of iPSCs as a technology of promise in the broader research space around neurodegenerative diseases. In this context, the research literature, and notably review articles, play an important role as rhetorical tools mobilising expectations, interest and funding, and establishing the future scope of the technology. As Kerr (2000) argues, the research literature remains a potent source for the state of knowledge in a field. Moreover, the rhetorical function of reviews represents a key means through which (primarily senior) researchers work to shape the literature of a field into a coherent narrative, with the goal of enlisting the support of readers, extending the story and shaping research directions (Hedgecoe 2004; Myers 1991). This paper thus draws on an analysis of 28 review and commentary papers on the use of induced pluripotent stem cell research as models in neurodegenerative disease research published between 2008 and 2014. It examines how researchers describe and position the iPSC research within these documents and support or contest the promise of the technology. In following discussions through the literature, it also draws on a small body of historical literature related to the 'premature ageing' syndrome Hutchison-Gilford progeria.

\section{The problem of ageing}

Age is the most significant risk factor for dementias and neurodegenerative diseases, with Alzheimer's the most common. However, the history of Alzheimer's disease research illustrates the contested relationship between ageing and neurodegeneration (Lock 2013). When first described by Alois Alzheimer in 1906, Alzheimer's disease was defined as a 'presenile dementia' characterised by distinctive pathological featuresamyloid plaques and neurofibrillary tangles. This definition of Alzheimer's disease was 'synchronic' (Dillman 2000), in that its presence in younger people distinguished them from other people at the same time of life. As such, it could be understood as distinct from senility, understood as part of the 'normal' ageing process and of varying severity, with "no sharp lines, no mini-mental status exams, no differential diagnosis" dividing “'normal' senility from senile dementia" (Holstein 1997, 163).

Between the mid-1930s and the 1950s, and particularly following World War II, research interest in senile dementia grew significantly and it became more clearly delineated from 'normal' ageing (Ballenger 2006). Initially, Alzheimer's disease remained distinct and was consequently understood to be rare. However, from the 1960 s onwards a series of social, political and technoscientific changes prompted a process of redefinition. The emergence of the 'Alzheimer's disease movement' brought technical, social, economic and political resources to bear on the 'myth of senility' and eliminated age as a defining criterion of disease. The new focus on 'Senile Dementia of the Alzheimer's Type' (SDAT) enabled the mobilisation of funds and resources for research on neurological diseases of ageing (Fox 1989).

The major consequence of the redefinition was to establish a new relationship between senility, senile dementia, Alzheimer's disease, and 'normal' ageing. SDAT was understood to be a later-onset version of Alzheimer's disease, defined in terms of neuropathology. 'Early onset' Alzheimer's disease, which was often familial, and 'late onset', sporadic forms of the condition were understood to be biologically equivalent, if often distinct in severity. This underpinned expectations of therapeutic advance associated with the identification and targeting of these shared biological processes. Importantly however, counter narratives continued to persist within public health and biogerontology, emphasising the centrality of the ageing process (Brayne and Calloway 1988; Lock 2013) and the limitations of a focus on discrete and specific aetiologies in an era of chronic, long-term illness (Moreira and Palladino 2009). 


\section{Modelling Alzheimer's disease}

The identification of Alzheimer's disease as involving a common process of pathogenesis regardless of age, associated with specific genetic mutations, provided new hopes for Alzheimer's disease research. In a 1992 paper John Hardy and Gerald Higgins set out the influential 'amyloid cascade' model of Alzheimer's disease progression. Starting from the fact that Alzheimer's disease occurred in elderly people and those with Downs syndrome who live to age 50, they outlined a biological pathway for Alzheimer's disease associated with the amyloid precursor protein gene, found on chromosome 21 . They concluded that the validation and long-term value of their disease model would be established through new mouse models:

"the ongoing development of transgenic animals ... should provide good models for experimental testing of key elements in the cascade" (Hardy and Higgins 1992, 185).

The promise of better models provided the foundation for the imagined future progress of research. The simplification and standardisation of diseases or conditions through the use of animal models - from drosophila to chimpanzees, but primarily mice and rats - is integral to the experimental life sciences and to the promise of 'translating' research into practice (Shostak 2007; Davies 2012; Birke 2012). Models create a new space of representation which enable complex phenomena to become tractable scientific objects (Rheinberger 2010), and in the process establish a new topology of disease as it is broken down into biological pathways or endophenotypes which can be mapped consistently across species. In turn, models themselves are able to circulate in standardised forms within scientific networks of exchange (Davies 2012). However, the epistemic value and limits of such models requires constant renegotiation (Nelson 2012; Lewis et al. 2012). The value of models is in turn defined by how these limits are defined and what is excluded. In the case of neuroscience, concerns revolve around the cognitive and biological differences between human and other brains (Rose and Abi-Rached 2013).

The promise of animal models of Alzheimer's disease, founded on a chain of biological equivalence between late-onset, familial forms of disease, and the replications of the genetic variants associated with the latter in mice, has yet to be realised. The limits and limitations of animal models of Alzheimer's disease are highlighted by the repeated ability of researchers to affect animal models of disease but not human disease itself - by some estimates, around 300 strategies to treat Alzheimer's disease have shown promise in mice, yet none has been effective in humans (Ashe and Zahs 2010). As a report of the EU Joint Programme on Neurodegenerative Diseases reflected in 2014, animal studies' "results are often encouraging, but when the new strategy is tested in the clinical setting - especially in large controlled clinical trials - enthusiasm fades away." (JPND Action Group 2014, 7).

\section{Modelling the brain}

While animal models are a repository for frustrated hopes, induced pluripotent stem cells are driving a renewed wave of hopeful and hyped futures, positioned by proponents as the answer to the problems of Alzheimer's disease research and indeed neuroscience more broadly. The addition of the 'Yamanaka factors', most commonly using a virus vector to insert them into the cell, 'reprograms' iPS cells to become 'pluripotent'. Pluripotency is central to the promise of stem cell technology, and was long seen as unique to embryonic stem cells (Eriksson 2012). From a pluripotent state cells can be re-differentiated into any of the range of cell types which make up the body or brain, including neurons. The further expression of further epigenetic factors directs cells across an 'epigenetic landscape' toward particular cellular 'lineages' (Pickersgill et al. 2013). The cells are subsequently grown in culture and allowed to differentiate, usually over a period of several weeks.

The hyperbolic promise of iPSCs is captured in the enthusiastic titles given to papers reviewing the technology, which describe "The Promise of iPSC-Derived Neurons" (Dolmetsch and Geschwind 2011) as "A Game Changer for Future Medicine" (Inoue et al. 2014). The perceived transformative potential of iPSCs for the neurosciences is captured in the concluding sentence of a review from researchers at the Salk Institute: 
"Neuroscientists in the past could not have imagined a scenario in which patient-derived neural cell types would be readily accessible to thousands of laboratories around the world, and researchers in the future will never imagine neuroscience without it." (Marchetto, Winner, and Gage 2010, R75; emphasis added)

The short term promise of iPSCs, which focusses not on their potential for regenerative medicine but as bioobjects to transform research practice, facilitate and enable research across conventional boundaries and be accessible for researchers regardless of location. The ability of these cells to objectify the characteristics of the patient body, leads some reviews to position IPS cells as an 'alternative human body' (Srikanth and YoungPearse 2014) which can be generated, manipulated, and regenerated at will. Furthermore, the ability to replicate and manipulate the human, patient, body allows processes which occurred prior to research to be captured and observed. As a 2013 commentary from a researcher at the Californian Regenerative Medicine Institute puts it:

"Producing pluripotent stem cells from adult or even aged fibroblasts feels like getting into a DeLorean and going back in time. However, instead of fiction using a lightning bolt combined with a critical speed of 88 miles per hour to go back in time, it appears that reality suggests all one needs are a few released factors or pluripotency genes which activate endogenous pluripotency pathways." (Svendsen 2013, R36)

Svendsen's commentary explicitly links the scientific success of Yamanaka with the science fiction of the Back to the Future films, opening up an ability to move back and forth through the life course, intervening in the past to influence the future, such that:

"human diseases can be played over and over again while interrogating real human molecular genetics, disease mechanisms or novel drugs." (Svendsen 2013, R33; emphasis added)

In this narrative, iPSCs are understood to offer unprecedented access to both 'real' biology and the 'real' past, in contrast to the simulations and reproductions offered by models. iPSCs offer the potential for biomedical research to return to earlier stages in life and in illness, making visible things that were unnoticed or unsought for at the time. Two features of this promise are particularly distinctive. The first is the specificity of stem cells which are, in theory, identical to those of the individual from which they are taken, and unique to that individual. Consequently, unlike animal models which replicate general biological processes they are able to stand in for the specific patient themselves, and as bio-objects can be moved, experimented upon, stored and re-differentiated again in ways in which the patient themselves cannot, in the same way as traditional immortal cell cultures (cf Landecker 2009a). Moreover, the translational potential of iPSCs relies on the correspondence between derived neurons and 'primary cells' in the body of the donor - both their equivalence to the diseased bodies from which skin cells are taken, and ability to substitute for the inaccessible cells of the brains of these bodies, as Jung et al. describe in their 2012 review:

"as a material of screening iPSCs are the exact human cells that are affected in the diseases, but not the unrelated immortalized cell lines artificially modified to mimic the disease" (Jung et al. 2012, 126; emphasis added)

IPS cells can be used to recapture lost youth, return aged bodies to their earlier state, and ultimately re-run the aging process - while all the time retaining their relations with the 'real' bodies from which they were taken. This relationship of equivalence motivates descriptions of iPSCs as 'the new patient' (Bellin et al. 2012), and erases the distinctions and oscillations between in vivo and in vitro work which were fundamental to twentieth century experimental systems in the life sciences (Rheinberger 2010).

The grounding of IPSCs in the bodies and lives of donors is reflected in representations of 'translation' that accompany reviews of IPS cell technology and depictions of how it will work in future. Unlike common (and widely-critiqued) linear depictions of translational movement from bench to bedside (Laan and Boenink 2012), these are loops, which return to the very people who form the basis of research. These representations point to some of the complexity of the relationship between the laboratory and the clinic in biomedicine. In some senses, they capture iterative interactions between bench and bedside such as those described by Martin and colleagues in the context of haematopoietic stem cells (P. Martin, Brown, and Kraft 2008). However, they also challenge the position of the patient themselves, as their attributes and identities emerge from and are re- 
written through these circulations between the bench and the bedside, and between their biological past and present (cf Latimer 2013) .

Crucially, temporality is missing from these translational loops. The patient becomes the bearer of a static disease state, but the ability to model or intervene in this state relies on the ability to capture and reproduce the temporality of their body. This includes the changes and encounters that constitute, drive and influence processes of neurodegeneration and ageing - as well as the research process itself. Moreover, the description of the ability to re-run disease above assumes that the disease manifested in the body from which the cells were taken is latent within these cells, and that successive reiterations of this cell-body's time will result in the reproduction of the disease. However, the reproduction of this temporality challenges the potential of the technology.

\section{Modelling the 'aged' brain}

The development and commercialisation of stem cell research and regenerative medicine has been spurred by the promise of a 'fountain of youth' (Brown 2005). Yet, while embryonic cells (by definition) represent the start of life, iPS cells have a more complex relationship with the lifespan. Okano and Yamanaka point out that "[a] potential problem with current iPS cell technologies in modelling late-onset neurodegenerative diseases is the difficulty in obtaining age-related phenotypes in a relatively short timeframe." $(2014,7)$. As described earlier, age has been systematically excluded, particularly from the characteristic features of Alzheimer's disease. However, ageing is reintroduced in challenges to the potential of iPSCs to capture and model late-onset disease, and in efforts to reimagine this promise.

Ageing is presented as an 'obstacle' to the development of iPSC models of neurodegenerative disorders (Garber 2014). The challenge is inseparable from the regenerative nature of the technology - it arises because of the process of inducing pluripotency 'scrubs' IPS cells of the 'markers' understood to be indicative of biological ageing such as mitochondrial fitness, telomere length and epigenetic changes (cf Moreira 2015). Consequently, while still in one sense the cells of the bodies from which they were taken, they are also those of an alternative embryonic version. As one paper puts it, reprogramming "resets their identity back to an embryonic age" (Miller et al. 2013, 691).

The identification of 'missing' features of ageing suggest that the shared 'genetic background' on which the equivalence of IPSC and primary cells is based is not enough - they must share a past. This loss of ageing calls the promise of the technology into question. Thus Brennand (2013) argues that "it may be more accurate to state that current hiPSC-based studies have modelled genetic predisposition to disease, rather than the disease state itself" (Brennand 2013, 635). The suggestion is that iPSC models are modelling earlier points in a patient's biological life-course, rather than the 'old' individuals from which they were taken.

The regenerative promise of stem cell therapy thus becomes its problem as the 'aged' population in the clinic becomes an embryonic population in the dish, and diseases such as Alzheimer's or Parkinson's are temporally distancing even as they become biologically accessible. Consequently, critics argue that "It's not reasonable to assume that Parkinson's disease will appear in an immature embryonic fetal neuron ... unless we grow the cells for maybe 70 years." (Isacson in Garber 2014). Another suggests that "with current techniques, we would typically have to grow pluripotent stem cell-derived cells for 60 or more years in order to model a late-onset disease" (Studer quoted in Cell Press 2013).

Because of the rejuvenation of IPS cells, their potential as a platform for modelling human brain ageing and disease is called into question. The argument is not about the ability of the model to replicate what it purports to, but about its ability to do so now, or within the time of laboratory work and political imperatives. The question becomes not whether IPS cells can model human neurons, but whether there is time in the laboratory for this to happen - how to fit a lifetime of ageing into the lived times of the laboratory, clinic, funding cycles, careers, publication schedules and G8 ambitions. 


\section{Re-degeneration: Finding time again}

The problem of ageing is neither fatal to the promise of iPSCs for research into neurodegeneration, nor the only challenge the technology faces. However, it challenges the equivalence of the reprogrammed cell and that of the donor and prompts a reconfiguration of the iPSC bio-object. On one hand, it has prompted research into alternative approaches with greater temporal fidelity, including direct neuronal conversion - in which neurons are generated from fibroblasts without the intermediate 'scrubbing' stage (Koch 2015; Yang et al. 2011). Alternative approaches focus on refining and renewing the promise of iPSC models. Thus, the paper by Brennand (2013) introduced above is a commentary on another body of work that introduces an approach to 'inducing' ageing, and the search for 'the most mature-looking neuron'. This work highlights the imperative to model not just disease, but ageing itself.

In late 2013, a group of researchers led by Lorenz Studer at the Sloan-Kettering Institute in New York described a new approach to modelling late-onset disease. In a paper and accompanying patent applications, they proposed reproducing the biological hallmarks of ageing described above by means of a protein, progerin (Miller et al. 2013). The paper received wide attention. It was selected by Cell Stem Cell as one of their highlights of 2013 (Sweet 2014) and was depicted on the journal cover image with an image that recapitulated Svendson's representation of iPSCs as time-travel. In its depiction of a 'Back to the Future' Delorean time machine in which the clock is set to send a "young" iPSC-derived cell to an aged state" ${ }^{\prime \prime}$. the image again implies the ability of researchers to move and intervene within the prior life-time of a patient. Studer summarised his group's research in a short commentary in the journal Aging in early 2014:

"... with progerin-induced aging, we can accelerate [the] process down to a period of a few days or weeks. This should greatly simplify the study of many late-onset diseases that are of such great burden to our aging society." (Miller and Studer 2014, 246)

Progerin appears as a technological solution that enables movements back and forth in time within the translational loop described above. It introduces the possibility of modelling not just 'real' disease cells, but what is variously referred to as 'ageing', age-like or simply ageing. As Studer and colleagues expand in a subsequent, more explicitly promissory piece, it offers the possibility to 'transform studies of aging' by enabling the "precise programming of cellular age" (Studer, Vera, and Cornacchia 2015).

\section{'Premature' Ageing}

The shift to 'ageing' rather than disease as characteristic of the iPSC bio-object returns discussion to the second fault-line identified in the case of Alzheimer's disease, that of the relationship between neurodegeneration and time, normal and pathological ageing. The progerin protein used by Miller and Studer was originally identified in individuals with Hutchinson-Gilford progeria syndrome (HGPS), a rare genetic disorder occurring at a rate of 1 per 4 million live births (Burtner and Kennedy 2010). HGPS results from a mutation in the gene coding for lamin-A, a protein involved in DNA repair. As damage to DNA increases during the 'normal' course of ageing, it is suggested that similar mechanisms may be in action in the case of HGPS. As such, the relationship between HGPS and 'normal' ageing recapitulates that between familial and sporadic forms of Alzheimer's disease, in which the 'rare' represents the 'common'. However, as in the case of Alzheimer's disease, this relationship is unstable. While Studer and colleagues refer to HGPS simply as a "premature aging disorder" (Miller and Studer 2014, 246), its relationship between normal ageing has long been debated (Dreesen and Stewart 2011).

HGPS is an exceedingly rare disease, with few cases reported prior to recent internet-enabled efforts to build a worldwide community of affected individuals, and little long-term research interest or investment. The intermittent papers that have appeared on HGPS and progeria since its first description have often reflected on its relationship with 'normal' ageing. The classic description of the disease was developed by Hastings Gilford in a 1902 paper. Gilford suggested the term progeria, contrasting it with a second condition, that of 'continuous youth' (which he dubbed 'ateleiosis') and with other forms of 'senilism' (Gilford 1902). Gilford's 
1896 case report on a 'mixture of mixed premature and immature development' reviewed the progress of the patient described by Hutchison and introduced a new patient, A.R.:

“A. R- was first brought to me in January, 1891, when he was a little over fourteen years old, but his appearance as he came into my room was suggestive either of a child of five or of a wizened and dwarfish old man. On the one hand, his size (height 1'04 m., weight 1634 kilos.), manner of dress, and the fact that he was brought by his sister in a mail-cart, drove one at once to the conclusion that he was a child. On the other hand, had he come by himself in the clothes and other accessories of old age, I think there are few who would have detected the deception." (Gilford 1897, 20, emphasis added)

The relationship between progeria and old age is here one of physical resemblance - old mannishness rather than being an old man, and, as the title of the report suggests it exists alongside youth, rather than replacing it. Gilford describes how the understanding of the patient as old or young depends on which features are emphasised, and how these are shaped by clothing and 'accessories'. However, his report emphasises that people with the condition seemed cognitively normal, and the post-mortem included in his 1897 paper described how "The brain was normal in every respect" (Gilford 1897, 30). Similarly, more recent reviews have argued that, while many of the physiological changes of ageing are seen in HGPS, common features of ageing in the general population are not (G. M. Martin and Oshima 2000). These include cognitive decline and the pathological changes associated with Alzheimer's disease.

In a later review of the neurology of old age, which considered HGPS alongside other neurological conditions associated with ageing, Macdonald Critchley inverted the current relationship between progeria and ageing in distinguishing it from 'premature' senility of the type observed in (then rare) Alzheimer's disease. Placing the focus on cognitive and anatomical features of affected individuals, but emphasising the lack of available data, he argued that this was 'precocious' senility, in which characteristics associated with old age appear in the very young. He concluded that:

"The child with progeria is not so much one which has run through the gamut of the years with astonishing rapidity, but rather one who has, in some respects, never grown up." (Critchley 1931, 1335)

Twenty years later, a review of premature ageing conditions was more equivocal, recognising the potential of the condition for understanding the 'normal' ageing process in an accelerated form. Nevertheless, it also points out that the process of premature ageing is coeval with 'normal' development:

"We can watch the occurrence, over a span of 10 or 15 years, of changes of senility which would normally take five or six times as long to develop. Were we to understand the pathology considerable light might be shed on the processes of ageing. The changes are not, however, merely those of senility. They are those of senility imposed at an infantile stage of development so that infantile characteristics persist side by side with senile ones" (Thomson and Forfar 1950, 232)

Two important conclusions derive from these descriptions. First, 'old age' and 'youth' are not mutually exclusive descriptors of HGPS. They refer to characteristic features associated with each stage, rather than the process (and timescale) over which these features have emerged. Second, an understanding of HGPS as 'premature ageing' is a rhetorical or metaphorical as much as a factual description.

\section{Aged and ageing brains}

The promise of iPSC technology resides in its ability to close the 'translational loop', bridging clinical care and basic science. Researchers describe how iPSCs free them from the constraints or limits of animal models by providing access to 'real' human neurons, originating in 'real' patients' bodies. However, as I have described, establishing, supporting and reimagining this narrative requires the repeated reworking of iPS cells, the patient and the relationship between diseases of ageing and 'diseased ageing'. As the futures of induced pluripotent stem cells are projected and contested, new understandings of ageing and neurodegeneration emerge. The specific qualities and characteristics associated with these consequently become indicative of 'ageing', as illustrated by the example of HGPS. 
The adoption of HGPS as an 'accelerated' form of normal ageing within stem cell models perpetuates their research potential. However, the unstable relationship between progeria and 'normal' ageing requires the constant reminder that "... this strategy enhances age-specific features rather than providing a 'realistic' model of aging or neurodegeneration. ${ }^{\prime \prime i}$. This molecularised understanding of ageing establishes the potential of iPSCs as bio-objects, but in the process redefines the lived experience of ageing as a cellular process with distinctive molecular epigenetic hallmarks. Reproducing these hallmarks is understood to replicate the 'duration' (Adam 2006) over which lived and embodied ageing occurs, and which results in neurodegeneration. This approach reifies what gerontologist Jan Baars (2010) describes as a chronological, causal concept of time.

The biological equivalence between 'long' and 'short' duration ageing posited by the use of progerin establishes the state of being 'aged' as a constant, regardless of the process of 'getting old'. Using stressed cells to recapitulate the ageing process cuts ageing loose from the duration of lived experiences and the artefacts and occasions through which older people and 'old age' are constituted, in favour of being a condition of being 'aged' (cf Latimer 1997). However, 'induced ageing' also reinforces stereotypical understandings of ageing for both for those we consider 'old' on the basis of lived time, and those understood to be 'old before their time'. The ability of progerin to regenerate the promise of iPSC models constitutes progeria as 'diseased ageing', rather than as a disease of childhood. Yet as the early literature around Hutchinson-Gilford progeria emphasised, progerian 'ageing' is identified not only by its biological characteristics but by its inappropriateness, by its appearance at the wrong time in people who are emphatically not 'old'. In making relations of equivalence between ageing and HGPS, the latter becomes ever more closely tied to the former. Finally, the promise of stem cell medicine has long been closely tied to apocalyptic predictions of impending economic doom connected with the ageing population (Cooper 2006). The materialisation and standardisation of ageing as a sequence of biological changes contributes to establishing the promise of iPSCs as a bio-object for ageing research. In becoming divorced from the body, 'ageing in the dish' can be subjected to changes in pace, rhythm and intensity, able to circulate and be exchanged. 


\section{References}

Adam, B. 2006. "Time." Theory, Culture \& Society 23 (2-3): 119-26. doi:10.1177/0263276406063779.

Ashe, Karen H, and Kathleen R Zahs. 2010. "Probing the Biology of Alzheimer's Disease in Mice." Neuron 66 (5): 631-45. doi:10.1016/j.neuron.2010.04.031.

Baars, J. 2010. "Philosophy of Aging, Time, and Finitude." In A Guide to Humanistic Studies in Aging : What Does It Mean to Grow Old?, edited by T. Cole, R. Ray, and R. Kastenbaum, 105-20. Baltimore: Johns Hopkins University Press.

Ballenger, JF. 2006. Self, Senility, and Alzheimer's Disease in Modern America: A History. Baltimore/London: Johns Hopkins University Press.

Behuniak, SUSAN M. 2011. "The Living Dead? The Construction of People with Alzheimer's Disease as Zombies." Ageing and Society 31 (1). Cambridge University Press: 70-92. doi:10.1017/S0144686X10000693.

Bellin, Milena, Maria C Marchetto, Fred H Gage, and Christine L Mummery. 2012. "Induced Pluripotent Stem Cells: The New Patient?" Nature Reviews. Molecular Cell Biology 13 (11). Nature Publishing Group, a division of Macmillan Publishers Limited. All Rights Reserved.: 713-26. doi:10.1038/nrm3448.

Birke, L. 2012. "Animal Bodies in the Production of Scientific Knowledge: Modelling Medicine." Body \& Society 18 (3-4): 156-78. doi:10.1177/1357034X12446379.

Borup, M, N Brown, and K Konrad. 2006. "The Sociology of Expectations in Science and Technology." Technology Analysis \& Strategic Management

Brayne, Carol, and Paul Calloway. 1988. "Is Alzheimer's Disease Distinct from Normal Ageing?" The Lancet 332 (8609): 514-15. doi:10.1016/S0140-6736(88)90166-3.

Brennand, Kristen J. 2013. "Inducing Cellular Aging: Enabling Neurodegeneration-in-a-Dish." Cell Stem Cell 13 (6): 635-36. doi:10.1016/j.stem.2013.11.017.

Brown, N. 2005. "Shifting Tenses: Reconnecting Regimes of Truth and Hope." Configurations 13 (3): 331-55..

Brown, N, and M Michael. 2003. "A Sociology of Expectations: Retrospecting Prospects and Prospecting Retrospects." Technology Analysis and Strategic Managment 15 (1): 3-18.

Burtner, Christopher R, and Brian K Kennedy. 2010. “Progeria Syndromes and Ageing: What Is the Connection?" Nature Reviews. Molecular Cell Biology 11 (8).: 567-78. doi:10.1038/nrm2944.

Cameron, David. 2014. "Global Dementia Legacy Event: David Cameron's Speech." Prime Minister's Office, 10 Downing Street, The Rt Hon David Cameron MP and Department of Health.

Cell Press. 2013. "Scientists Accelerate Aging in Stem Cells to Study Age-Related Diseases like Parkinson's." ScienceDaily.

Cooper, M. 2006. "Resuscitations: Stem Cells and the Crisis of Old Age." Body \& Society 12 (1): 1-23. doi:10.1177/1357034X06061196.

Critchley, M. 1931. "The Neurology of Old Age." The Lancet 217 (5625): 1331-37. doi:10.1016/S01406736(00)46849-2.

Davies, G. 2012. "What Is a Humanized Mouse? Remaking the Species and Spaces of Translational Medicine." Body \& Society. http://bod.sagepub.com/content/18/3-4/126.short.

Dillman, R. 2000. "Alzheimer Disease: Epistemological Lessons from History?" In Concepts of Alzheimer Disease: Biological, Clinical, and Cultural Perspectives, edited by P. Whitehouse, K. Maurer, and J. Ballenger, 129-57. Baltimore/London: The Johns Hopkins University Press.

Dolmetsch, Ricardo, and Daniel H Geschwind. 2011. "The Human Brain in a Dish: The Promise of iPSC-Derived Neurons." Cell 145 (6): 831-34. doi:10.1016/j.cell.2011.05.034.

Dreesen, Oliver, and Colin L Stewart. 2011. "Accelerated Aging Syndromes, Are They Relevant to Normal Human Aging?" Aging 3 (9): 889-95. tract.

Eriksson, L. 2012. "Pluripotent Promises: Configurations of a Bio-Object." Bio-Objects: Life in the 21st Century. 
Farnham: Routledge

Fox, P. 1989. "From Senility to Alzheimer's Disease: The Rise of the Alzheimer's Disease Movement." The Milbank Quarterly 67 (1): 58-102.

Franklin, S. 2006. "The Cyborg Embryo Our Path to Transbiology." Theory, Culture \& Society.

Garber, Ken. 2014. “Between Disease and a Dish." Nature Biotechnology 32 (8).: 712-15. doi:10.1038/nbt.2977.

Gilford, H. 1897. "On a Condition of Mixed Premature and Immature Development." Medico-Chirurgical Transactions 80 (January): 17-46.25.

-_-. 1902. "Infantilism and Senilism." The British Medical Journal.

Hardy, J A, and G A Higgins. 1992. "Alzheimer's Disease: The Amyloid Cascade Hypothesis." Science (New York, N.Y.) 256 (5054): 184-85..

Hauskeller, Christine, and Susanne Weber. 2011. "Framing Pluripotency: iPS Cells and the Shaping of Stem Cell Science." New Genetics and Society 30 (4). Routledge: 415-31. doi:10.1080/14636778.2011.592007.

Hedgecoe, A. 2004. The Politics of Personalised Medicine: Pharmacogenetics in the Clinic. Cambridge: Cambridge University Press.

- - . 2006. "Pharmacogenetics as Alien Science: Alzheimer's Disease, Core Sets and Expectations." Social Studies of Science 36 (5): 723-52. doi: 10.1177/0306312706059746.

Hedgecoe, A, and P Martin. 2003. "The Drugs Don't Work: Expectations and the Shaping of Pharmacogenetics." Social Studies of Science 33 (3): 327-64.

Holmberg, Tora, Nete Schwennesen, and Andrew Webster. 2011. "Bio-Objects and the Bio-Objectification Process." Croatian Medical Journal 52 (6). Medicinska Naklada: 740-42. doi:10.3325/cmj.2011.52.740.

Holstein, Martha. 1997. “Alzheimer's Disease and Senile Dementia, 1885-1920: An Interpretive History of Disease Negotiation." Journal of Aging Studies 11 (1): 1-13. doi:10.1016/S0890-4065(97)90008-6.

Inoue, Haruhisa, Naoki Nagata, Hiromi Kurokawa, and Shinya Yamanaka. 2014. “iPS Cells: A Game Changer for Future Medicine." The EMBO Journal 33 (5). EMBO Press: 409-17. doi:10.1002/embj.201387098.

JPND Action Group. 2014. "Experimental Models for Neurodegenerative Diseases."

Jung, Yong Wook, Eriona Hysolli, Kun-Yong Kim, Yoshiaki Tanaka, and In-Hyun Park. 2012. "Human Induced Pluripotent Stem Cells and Neurodegenerative Disease: Prospects for Novel Therapies." Current Opinion in Neurology 25 (2): 125-30. doi:10.1097/WCO.0b013e3283518226.

Koch, Philipp. 2015. “Direct Conversion Provides Old Neurons from Aged Donor's Skin." Cell Stem Cell 17 (6): 637-38. doi:10.1016/j.stem.2015.11.009.

Laan, AL van der, and M Boenink. 2012. "Beyond Bench and Bedside: Disentangling the Concept of Translational Research." Health Care Analysis.

Landecker, H. 2009a. Culturing Life: How Cells Became Technologies. Harvard University Press.

- - . 2009b. "Living Differently in Time: Plasticity, Temporality and Cellular Biotechnologies." Technologized Images: Technologized Bodies.

Latimer, J. 1997. "Figuring Identities: Older People, Medicine and Time." In Critical Approaches to Ageing and Later Life, edited by A. Jamieson, S. Harper, and C. Victor, 143-59. Milton Keynes: Open University Press.

- - - 2013. The Gene, the Clinic, and the Family: Diagnosing Dysmorphology, Reviving Medical Dominance. Abingdon: Routledge.

Lewis, J., P. Atkinson, J. Harrington, and K. Featherstone. 2012. "Representation and Practical Accomplishment in the Laboratory: When Is an Animal Model Good-Enough?" Sociology 47 (4): 776-92. doi:10.1177/0038038512457276.

Lock, Margaret. 2013. The Alzheimer Conundrum: Entanglements of Dementia and Aging. Princeton: Princeton University Press. 
Maienschein, Jane, Mary Sunderland, Rachel A Ankeny, and Jason Scott Robert. 2008. "The Ethos and Ethics of Translational Research." The American Journal of Bioethics : AJOB 8 (3). Routledge: 43-51. doi:10.1080/15265160802109314.

Marchetto, Maria C N, Beate Winner, and Fred H Gage. 2010. "Pluripotent Stem Cells in Neurodegenerative and Neurodevelopmental Diseases." Human Molecular Genetics 19 (R1): R71-6. doi:10.1093/hmg/ddq159.

Martin, G M, and J Oshima. 2000. "Lessons from Human Progeroid Syndromes." Nature 408 (6809): 263-66. doi:10.1038/35041705.

Martin, P, N Brown, and A Kraft. 2008. "From Bedside to Bench? Communities of Promise, Translational Research and the Making of Blood Stem Cells." Science as Culture. http://www.tandfonline.com/doi/abs/10.1080/09505430701872921.

Martin, P, N Brown, and A Turner. 2008. "Capitalizing Hope: The Commercial Development of Umbilical Cord Blood Stem Cell Banking." New Genetics and Society 27 (2). Routledge: 127-43. doi:10.1080/14636770802077074.

Metzler, Ingrid, and Andrew Webster. 2011. "Bio-Objects and Their Boundaries: Governing Matters at the Intersection of Society, Politics, and Science." Croatian Medical Journal 52 (5). Medicinska Naklada: 64850. doi:10.3325/cmj.2011.52.648.

Miller, Justine, Yosif M Ganat, Sarah Kishinevsky, Robert L Bowman, Becky Liu, Edmund Y Tu, Pankaj K Mandal, et al. 2013. "Human iPSC-Based Modeling of Late-Onset Disease via Progerin-Induced Aging." Cell Stem Cell 13 (6): 691-705. doi:10.1016/j.stem.2013.11.006.

Miller, Justine, and Lorenz Studer. 2014. "Aging in iPS Cells." Aging 6 (4): 246-47. http://www.pubmedcentral.nih.gov/articlerender.fcgi?artid=4032792\&tool=pmcentrez\&rendertype=abs tract.

Moreira, Tiago. 2015. “Unsettling Standards: The Biological Age Controversy.” The Sociological Quarterly 56 (1): 18-39. doi:10.1111/tsq.12079.

Moreira, Tiago, and Paolo Palladino. 2009. “Ageing between Gerontology and Biomedicine." BioSocieties 4 (4). Nature Publishing Group: 349-65. doi:10.1017/S1745855209990305.

Myers, G. 1991. "Stories and Styles in Two Molecular Biology Review Articles." Textual Dynamics of the Professions: Historical and ....

National Institute on Aging. 2012. "The National Plan to Address Alzheimer's Disease." https://www.nia.nih.gov/alzheimers/publication/2012-2013-alzheimers-disease-progressreport/national-plan-address-alzheimers.

National Institutes of Health. 2015. "Reaching for a Cure: Alzheimer's Disease and Related Dementias Research at NIH." Bypass Budget Proposal for Fiscal Year 2017. National Institutes of Health.

Nelson, N. C. 2012. "Modeling Mouse, Human, and Discipline: Epistemic Scaffolds in Animal Behavior Genetics." Social Studies of Science 43 (1): 3-29. doi:10.1177/0306312712463815.

OECD. 2015. "Enhancing Translational Research and Clinical Development for Alzheimer's Disease and Other Dementias." OECD Science, Technology and Industry Policy Papers. Paris: OECD Publishing.

Okano, Hideyuki, and Shinya Yamanaka. 2014. "iPS Cell Technologies: Significance and Applications to CNS Regeneration and Disease." Molecular Brain 7 (1): 22. doi:10.1186/1756-6606-7-22.

Pickersgill, Martyn, Jörg Niewöhner, Ruth Müller, Paul Martin, and Sarah Cunningham-Burley. 2013. “Mapping the New Molecular Landscape: Social Dimensions of Epigenetics." New Genetics and Society 32 (4). Routledge: 429-47. doi:10.1080/14636778.2013.861739.

Prainsack, Barbara, Ingrid Geesink, and Sarah Franklin. 2008. "Stem Cell Technologies 1998-2008: Controversies and Silences." Science as Culture 17 (4). Routledge: 351-62. doi:10.1080/09505430802514851.

Rheinberger, Hans-Jörg. 2010. An Epistemology of the Concrete. Edited by Joseph Dumit. Duke Books. Duke University Press. doi:10.1215/9780822391333. 
Robertson, Ann. 1990. "The Policies of Alzheimer's Disease: A Case Study in Apocalyptic Demography." International Journal of Health Services 20 (3). SAGE Publications: 429-42. doi:10.2190/C8AE-NYC12R98-MHP1.

Rose, NS, and JM Abi-Rached. 2013. Neuro: The New Brain Sciences and the Management of the Mind..

Shostak, S. 2007. "Translating at Work Genetically Modified Mouse Models and Molecularization in the Environmental Health Sciences." Science, Technology \& Human Values.

Srikanth, P, and TL Young-Pearse. 2014. "Stem Cells on the Brain: Modeling Neurodevelopmental and Neurodegenerative Diseases Using Human Induced Pluripotent Stem Cells." Journal of Neurogenetics.

Studer, Lorenz, Elsa Vera, and Daniela Cornacchia. 2015. "Programming and Reprogramming Cellular Age in the Era of Induced Pluripotency." Cell Stem Cell 16 (6): 591-600. doi:10.1016/j.stem.2015.05.004.

Svendsen, Clive N. 2013. "Back to the Future: How Human Induced Pluripotent Stem Cells Will Transform Regenerative Medicine." Human Molecular Genetics 22 (R1): R32-8. doi:10.1093/hmg/ddt379.

Sweet, Deborah J. 2014. “Keeping Score.” Cell Stem Cell 14 (6): 691-92. doi:10.1016/j.stem.2014.05.015.

Thomson, J, and J O Forfar. 1950. "Progeria (Hutchinson-Gilford Syndrome). Report of a Case and Review of the Literature." Archives of Disease in Childhood 25 (123): 224-34.

Vermeulen, N, S Tamminen, and A Webster. 2012. Bio-Objects: Life in the 21st Century. Farnham: Routledge.

Wainwright, Steven P, Mike Michael, and Clare Williams. 2008. "Shifting Paradigms? Reflections on Regenerative Medicine, Embryonic Stem Cells and Pharmaceuticals." Sociology of Health \& IIIness 30 (6): 959-74. doi:10.1111/j.1467-9566.2008.01118.x.

Yang, Nan, Yi Han Ng, Zhiping P Pang, Thomas C Südhof, and Marius Wernig. 2011. “Induced Neuronal Cells: How to Make and Define a Neuron." Cell Stem Cell 9 (6). Elsevier: 517-25. doi:10.1016/j.stem.2011.11.015. 